DOI: 10.5800/GT-2020-11-4-0501

\title{
STRUCTURAL FEATURES OF THE DEEP STRUCTURE OF THE SOUTHEASTERN YANA-KOLYMA FOLD SYSTEM FROM COMPLEX GEOPHYSICAL DATA
}

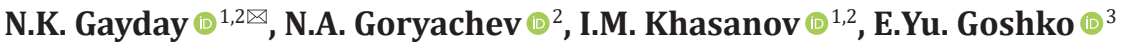

${ }^{1}$ North-Eastern State University, 13 Portovaya St, Magadan 685000, Russia

${ }^{2}$ Shilo North-East Interdisciplinary Scientific Research Institute, Far Eastern Branch of the Russian Academy of Sciences, 16 Portovaya St, Magadan 685000, Russia

${ }^{3}$ Siberian Research Institute of Geology, Geophysics and Mineral Resources, 67 Krasny Ave, Novosibirsk 630091, Russia

ABSTRACT. Ore deposits of the Magadan region are now in the focus of comprehensive studies as information on their deep structure is needed for both subsoil prospecting and regional development planning. This article presents the research results for the southeastern flank of the Yana-Kolyma orogenic belt. This area located at the junction with the Okhotsk-Koryak orogenic belt was investigated using the northeastern segment of the regional geophysical profile 3-DV. We analyzed the frequency-energy sections of the crust along the profile, 3D crustal density model of the entire study area, and magnetic, geoelectric and gravimagnetic characteristics of the crust. Complex data interpretation allowed tracing the crustal fault zones, areas wherein the crust material was strongly reworked, and zones of quasi-horizontal stratification. Considering the revealed features of the physical parameters of the crust material, we conclude that the currently accepted boundaries of individual tectonic blocks in the study area need to be adjusted. The northern boundary of the Balygychan uplift should be mapped along the Pautov fault. The Srednekansky branch of the Inyali-Debinsky synclinorium should be considered a transitional block that belongs to the Sugoi synclinorium, and its name should be changed to the Orotukan block.

KEYWORDS: interpretation; density section; frequency-energy section; geoelectric section; magmatism; Balygychan uplift; Orotukan block; geophysical reference profile

\section{RESEARCH ARTICLE}

Correspondence: Nataliya K. Gayday, nataly_mag@rambler.ru
Received: July 25, 2019

Revised: May 1, 2020

Accepted: May 14, 2020

FOR CITATION: Gayday N.K., Goryachev N.A., Khasanov I.M., Goshko E.Yu., 2020. Structural features of the deep structure of the Southeastern Yana-Kolyma fold system from complex geophysical data. Geodynamics \& Tectonophysics 11 (4), 697-709. doi:10.5800/GT-2020-114-0501 


\title{
СТРУКТУРНЫЕ ОСОБЕННОСТИ ГЛУБИННОГО СТРОЕНИЯ ЮГО-ВОСТОКА ЯНО-КОЛЫМСКОГО ОРОГЕННОГО ПОЯСА ПО РЕЗУЛЬТАТАМ КОМПЛЕКСНЫХ ГЕОФИЗИЧЕСКИХ ИССЛЕДОВАНИЙ
}

\author{
Н.К. Гайдай ${ }^{1,2}$, Н.А. Горячев ${ }^{2}$, И.М. Хасанов ${ }^{1,2}$, Е.Ю. Гошко
}

\author{
${ }^{1}$ Северо-Восточный государственный университет, 685000, Магадан, Портовая, 13, Россия \\ ${ }^{2}$ Северо-Восточный комплексный научно-исследовательский институт им. Н.А. Шило ДВО РАН, 685000 , \\ Магадан, Портовая, 16, Россия \\ ${ }^{3}$ Сибирский научно-исследовательский институт геологии, геофизики и минерального сырья, 630091, \\ Новосибирск, Красный пр-т, 67, Россия
}

АНнотАЦИЯ. В настоящее время в Магаданской области преимущественный интерес вызывают рудные месторождения. Информация о глубинном строении, недоступная прямым исследованиям, важна для планирования как региональных, так и поисковых работ. Это делает актуальным проведение комплексного изучения недр. Исследования выполнены для юго-восточного фланга Яно-Колымского орогенного пояса, в месте его сочленения с Охотско-Корякским орогенным поясом, в области расположения северо-восточного участка опорного геофизического профиля 3-ДВ. Использованы данные, полученные различными геофизическими методами: частотно-энергетические разрезы земной коры вдоль профиля 3-ДВ, трехмерная плотностная модель земной коры на всю исследуемую территорию, а также установленные магнитные, геоэлектрические и плотностные характеристики вещества земной коры. Результаты комплексной интерпретации позволили трассировать в земной коре зоны разрывных нарушений, области глубинной переработки вещества земной коры, а также области квазигоризонтальной расслоенности. Установленные особенности физических параметров вещества ставят вопрос о необходимости корректировки принятых в настоящее время границ отдельных тектонических блоков. Северную границу Балыгычанского поднятия следует провести по Паутовскому разлому. Среднеканская ветвь Иньяли-Дебинского синклинория может быть отнесена к Сугойскому синклинорию (переходный блок) и названа Оротуканским блоком.

КЛЮЧЕВЫЕ СЛОВА: интерпретация; плотностной разрез; частотно-энергетический разрез; геоэлектрический разрез; магматизм; Балыгычанское поднятие; Оротуканский блок; опорный геолого-геофизический профиль 3-ДВ

\section{1. ВВЕДЕНИЕ}

Информация о глубинном строении, недоступная прямым исследованиям, крайне важна для планирования как региональных, так и поисковых работ, особенно в свете смещения интересов в сторону поиска рудных месторождений, что ставит вопрос о необходимости проведения комплексных исследований недр.

Результаты сейсмических исследований методом отраженных волн в модификации общей глубинной точки (сейсмический разрез МОВ-ОГТ, сокращенно ОГТ) сегодня дают наиболее достоверную информацию о структуре земной коры. Однако ее гетерогенность осложняет интерпретацию сейсмических разрезов ОГТ. Таким образом, для однозначной интерпретации результатов эксперимента необходимо привлечение дополнительных геолого-геофизических данных.

Целью представляемой работы является проведение комплексной интерпретации ряда геофизических данных (частотно-энергетические, плотностные и геоэлектрические характеристики вещества земной коры), полученных различными исследователями для северо-восточного участка опорного геолого-геофизического профиля 3-ДВ (2350-2620 км) и прилегающих структур, и дальнейший анализ структурных особенностей глубинного строения юго-востока Яно-Колымской складчатой системы на основе полученных данных.

\section{2. КРАТКИЙ ОБЗОР ПРОБЛЕМЫ}

Рассматриваемая территория принадлежит юго-восточному флангу Яно-Колымского орогенного пояса, крупнейшей структуры северо-востока Азии [Chekhov, 2000; Parfenov et al., 2003; Khanchuk, 2006; Nokleberg et al., 2000], в месте его сочленения с Охотско-Корякским орогенным поясом [Khanchuk, 2006]. Здесь в строении Яно-Колымского пояса выделяются структуры КуларНерского террейна, представленные Иньяли-Дебинским синклинорием и Аян-Юряхским антиклинорием, а также Сугойским синклинорием. Охотско-Корякский орогенный пояс представлен Оротуканско-Балыгычанской структурой Вилигинского террейна [Khanchuk, 2006; Goryachev et al., 2016].

Для рассматриваемой территории (рис. 1) в предыдущие годы был выполнен большой объем геологогеофизических исследований. Согласно данным этих исследований, основные тектонические структуры территории достаточно определенно отражаются в геофизических материалах (гравитационное, магнитное поля и их трансформанты) и разделяются гравитационными ступенями различной интенсивности [Ganov, 2001; Chanyshev et al., 1984; Shpilko, 1991]. Линейные аномалии повышенных значений гравитационного поля, в основном северо-западного простирания, обусловлены структурно-вещественными неоднородностями кристаллического фундамента. Зоны повышенных 
градиентов поля силы тяжести и электропроводящие зоны соответствуют межблоковым, а иногда и магмоконтролирующим разломам. Локальные аномалии пониженных значений поля силы тяжести различной формы интенсивности и размеров фиксируют гранитоидные интрузии [Mikhailov, Goryachev, 2000; Goryachev, 2003; Surkov et al., 2007; Kuznetsov et al., 2010; Suvorov et al., 2014; и др.].

Кора основных структур по характеру электропроводности разделяется на три слоя. Первым элементом является сложно построенный (горизонтально-неоднородный) преимущественно высокоэлектропроводный (5-125 Ом·м) слой, который отождествляется с областью развития пород складчато-метаморфического комплекса. Со вторым элементом (диапазон глубин в среднем 8-20 км) - высокоомным основанием сопоставляются погруженные на глубину обширные (десятки километров в поперечнике) аномалии повышенных (125-2300 Ом·м) сопротивлений, трактуемых как комплекс метаосадочных пород основания (высокоомное основание). Третьим элементом иерархической структуры глубинной электропроводности является наиболее глубокозалегающий (более 20-25 км) литосферный проводящий слой. Сопротивление пород в его пределах (менее 5 Ом·м) в несколько раз меньше, чем в вышележащих породах. Положение этого проводящего слоя в пределах юго-востока Яно-Колымского орогенного пояса совпадает с коровым сейсмическим волноводом, выделенным по данным интерпретации отраженных волн [Khasanov, 2013].

Для значительной части территории определен морфоструктурный рисунок кровли высокоомного основания с глубиной 15-20 км [Khasanov, 2013]. Местами он осложнен локальными колоннами интенсивного

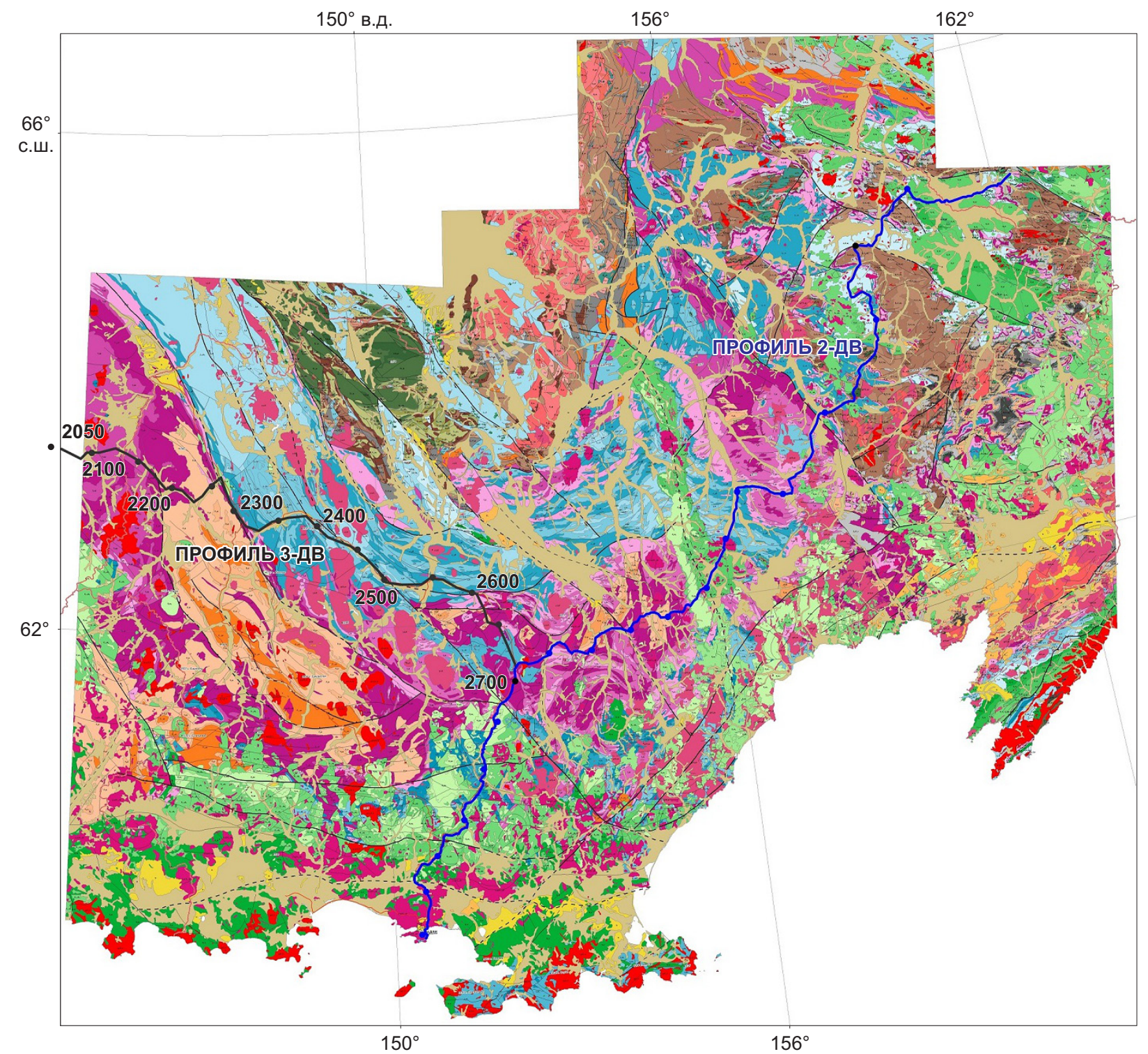

Рис. 1. Схема расположения региональных геофизических профилей 2-ДВ и 3-ДВ в пределах Магаданской области [Geological Map..., 1980].

Fig. 1. Schematic map of the Magadan region showing regional geophysical profiles 2-DV and 3-DV [Geological Map..., 1980]. 
магмонасыщения. Уточнено глубинное строение магматических очагов, установлена морфология части некоторых гранитоидных плутонов и их рудогенерирующее значение [Khasanov, Sharafutdinov, 2011].

Сейсмические исследования, проведенные в пределах контакта Иньяли-Дебинского синклинория и Омулевского поднятия, определили мощность земной коры в 38 км [Bol'shakov, 1988].

Однако и на сегодняшний день остается ряд нерешенных вопросов, которые требуют дополнительного изучения:

1. В генеральном плане, несмотря на большой объем материалов предшественников по глубинному строению территории, не проведен сравнительный анализ выявленных границ (верхоянский комплекс интрузивных образований, комплексы пород основания, средней и нижней коры), отображенных разными методами (геоэлектрика, грави- и магнитометрия, сейсмика). Это весьма актуально по причине появления новых данных по глубинному сейсмическому профилю 3-ДВ и материалов по профилю 2-ДВ [Surkov et al., 2007; Goryachev et al., 2007; Staroseltsev et al., 2007].

2. В локальном плане необходимо более четкое определение структурно-тектонического положения среднеканской ветви Иньяли-Дебинского синклинория (вполне вероятно, что с учетом геофизических характеристик данной области ее следует отнести к другой структуре). И на этом фоне требуется уточнение положения границ между такими тектоническими структурами, как Балыгычанское поднятие и Иньяли-Дебинский синклинорий.

Указанные аспекты в той или иной мере освещены предшественниками, но требуют дополнительных доказательств и четкой формулировки, что, собственно, и побудило авторов подготовить данную статью.

\section{3. МЕТОДИКА ИССЛЕДОВАНИЙ}

Комплексная интерпретация имеющихся геофизических данных осуществлялась путем совместного анализа результатов исследований, выполненных различными геофизическими методами: были использованы частотно-энергетические разрезы земной коры вдоль профиля 3-ДВ, трехмерная плотностная модель земной коры на всю исследуемую территорию, а также установленные магнитные, геоэлектрические и гравимагнитные характеристики вещества земной коры.

Динамические характеристики сейсмических волн являются уникальным источником информации о свойствах гетерогенной земной коры. Обработка гетерогенного сейсмического волнового поля осуществлена с использованием специальной компьютерной технологии «StreamSDS», разработанной в Сибирском научно-исследовательском институте геологии, геофизики и минерального сырья (АО «СНИИГГиМС», г. Новосибирск). Программный комплекс «StreamSDS» позволяет вычислять и визуализировать динамические характеристики отраженных волн в сейсмическом разрезе МОВ-ОГТ [Goshko et al., 2008, 2014].
Для построения трехмерной плотностной модели земной коры были использованы методы новой интерпретационной гравиметрии [Vaschilov, 2005], в основе которых лежат представления о преимущественно блоковой природе аномалий поля силы тяжести [Gayday, 2010]. С использованием специальной программы, созданной в лаборатории геофизики СВКНИИ ДВО РАН [Sakhno, 1983], рассчитываются глубины квазигоризонтальных границ расслоения в земной коре и плотностные характеристики отдельных ее блоков [Gayday, 2010]. Нижние ограничения аномалообразующих блоков позволяют оценить рельеф плотностной границы расслоения в земной коре [Gayday, 2017].

Определение абсолютных значений плотности пород основывается непосредственно на информации о плотности горных пород на поверхности. Плотность пород на глубине, в свою очередь, оценивается путем учета среднего градиента плотности, который для континентальных районов Магаданской области составляет 13.8 кг/( м $^{3}$ км) [Vaschilov, 1984].

При первичной обработке магнитотеллурических наблюдений использовался программный комплекс производства «Phoenix Geophysics» 000 «Северо-Запад». Его основные программы: «TimesSeriesViewer» для просмотра записей поля и «SSMT-2000» для первичной обработки.

Далее производилась интерактивная отбраковка данных и получение гладких кривых МТЗ, используемых затем в процедурах анализа и инверсии. Редакция осуществлялась в программе «MT-Corrector» (000 «Ceверо-Запад»). На этом этапе были построены гладкие сплайн-аппроксимации различных компонент тензора импеданса и типпера, которые затем были использованы на этапах анализа, инверсии и интерпретации данных МТ3.

Глубинная геоэлектрическая модель строилась с использованием алгоритмов 1D- и 2D-инверсии. Для построения разреза верхней части использовалась одномерная инверсия. Построенный разрез использовался как стартовая модель для двумерной инверсии. Ее стратегия предполагала поэтапное вовлечение различных компонент в оптимизационную схему. Сначала инвертировались квазипродольные кривые МТЗ, а затем «ансамбль» данных был расширен за счет привлечения квазипоперечных кривых, при этом модель, полученная на первом этапе, использовалась в качестве начального приближения на втором этапе [Sal'nikov et al., 2014].

Результаты гравиметрических и аэромагнитных данных геофизических наблюдений были обработаны программным комплексом спектрально-корреляционного анализа данных (КОСКАД) с целью выделения и уточнения зависимости геофизических параметров между собой. В ходе работ использовалась программа классификации, в которой реализован алгоритм разделения многомерных нормальных смесей, предложенный А.В. Петровым [Petrov, 1996]. Применение данной программы позволило выделить различные (в смысле вектора среднего) однородные области и подчеркнуть 
существующие между ними границы. При этом каждая из однородных (по двум указанным признакам) областей была связана с определенными геологическими объектами, однородными по геофизическим характеристикам. Конечное число классов (однородных областей) определялось опытным путем с использованием априорной геологической информации.

\section{4. РЕЗУЛЬТАТЫ ИССЛЕДОВАНИЙ}

Результаты комплексного анализа геолого-геофизических характеристик вещества земной коры (плотностные, магнитные, геоэлектрические и скоростные) позволили отметить отличительные особенности основных тектонических структур территории, в рамках которых выделяются различные по свойствам нижний и верхний структурные этажи. Ниже приведен анализ установленных особенностей для различных блоков территории - Иньяли-Дебинского синклинория, Оротуканского блока и Балыгычанского поднятия.
Верхний структурный этаж (складчато-метаморфический комплекс) Иньяли-Дебинского синклинория магнитный (от 50 до 500 нТл), магнитное поле дифференцированное, представляет собой чередование линейных локально положительных (до 500 нтл) и отрицательных (до -300 нТл) аномалий. По электрическим свойствам относительно низкоомный (в среднем 100 Ом·м), незначительно дифференцирован по удельному электрическому сопротивлению (УЭС) - от 30 до 150 Ом·м, осложнен как незначительными, так и крупными (в пределах Главного батолитового пояса) высокоомными (200-700 Ом·м) аномалиями (рис. 2). Мощность этажа около 20 км. В плотностном отношении

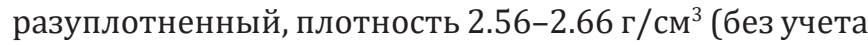
вертикального градиента, т.е. приведенная к поверхности) (рис. 3, б). Плотностная граница в среднем устанавливается на глубине 10-14 км (без учета сквозных зон разуплотнения). По скоростным характеристикам слой является низкоскоростным. Скорости изменяются

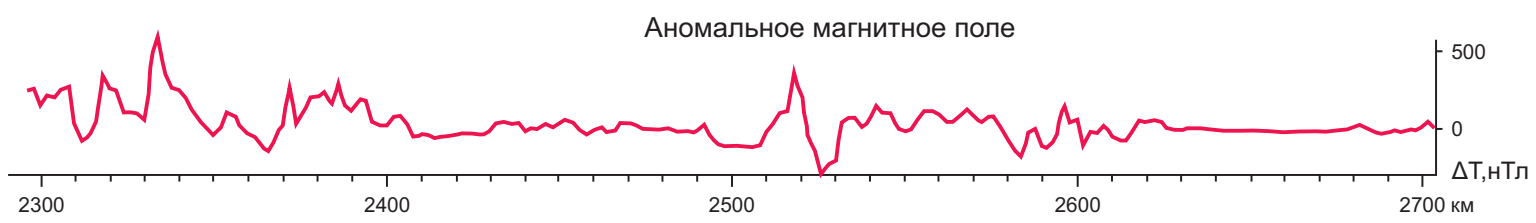

Аномальное гравитационное поле в редукции Буге
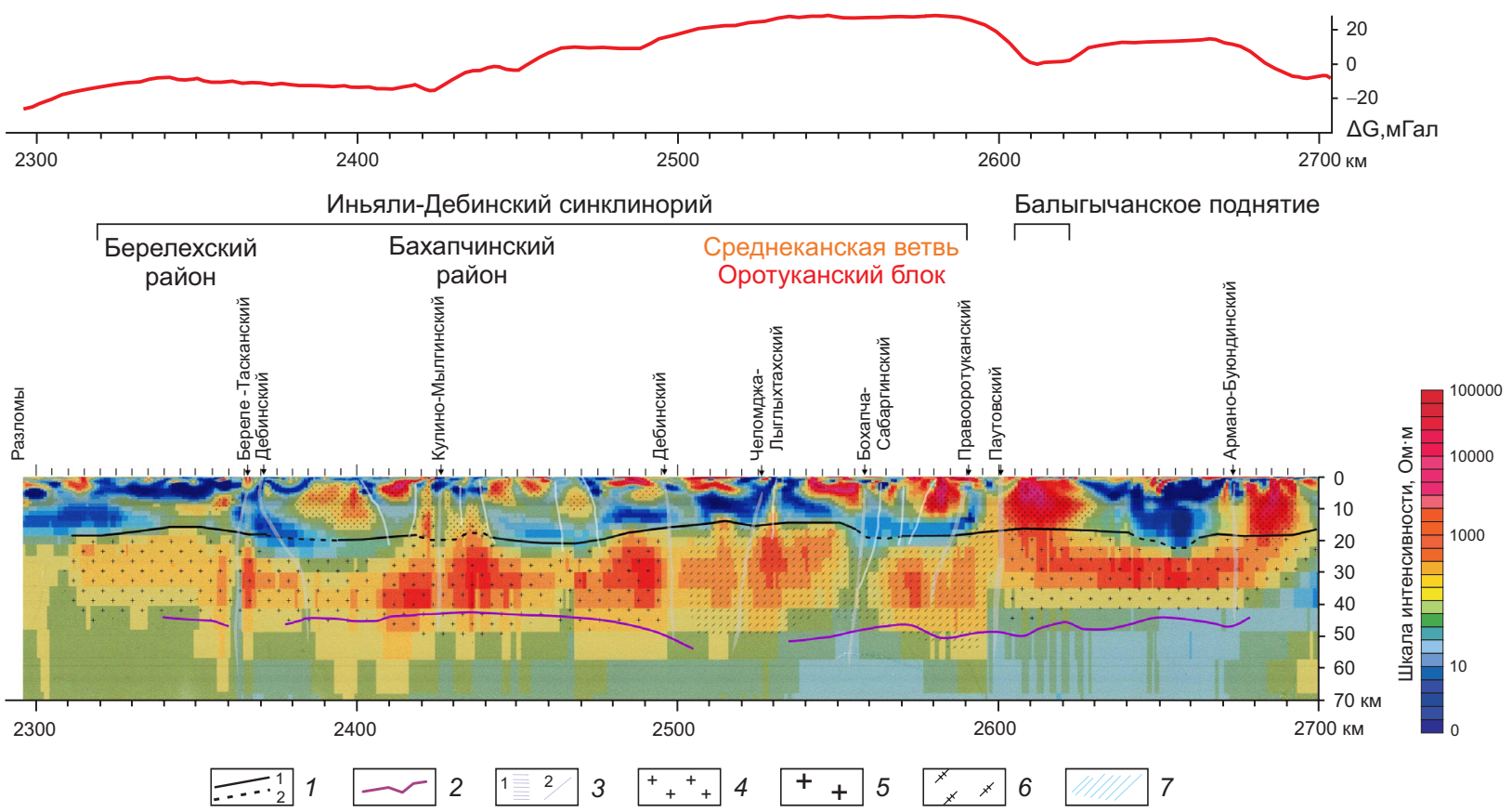

Рис. 2. Геоэлектрический разрез северо-восточного участка опорного профиля 3-ДВ.

1-2 - граница высокоомного основания - достоверная (1), предполагаемая (2); 2 - граница Мохоровичича (по данным сейсморазведки); 3 - разрывные нарушения - глубинного заложения (1), верхнекоровые (2); 4 - области магмонасыщения (гранитизации); 5-6 - средняя и нижняя кора (комплексы основания) сиалического (5) и мафического (6) состава; 7 - фрагменты литосферного проводящего слоя.

Fig. 2. Geoelectric section of the northeastern segment of the profile 3-DV.

1-2 - boundary of the high-resistance base - reliable (1), assumed (2); 2 - Moho boundary according to seismic data; 3 - deep-seated faults (1) and upper-crustal faults (2); 4- areas of magmatic saturation (granitization); 5-6 - middle and lower crust (base complexes) of sialic (5) and mafic (6) composition; 7 - fragments of the lithospheric conductive layer. 
в интервале 4.6-5.6 км/с. В верхней коре фиксируются три преломляющих скоростных границы (рис. 3, а). Первая граница устанавливается на глубине около 1 км и поднимается к дневной поверхности у р. Берелех на пикете 2350 км. Она характеризуется пластовой скоростью 4.5-5.0 км/с и граничной скоростью 5.2-5.6 км/с. Ниже расположена вторая граница с граничной скоростью 5.9-6.0 км/с. Ее глубина составляет 5 км, а в юго-восточном направлении она поднимается до глубинной отметки 2 км. Третья преломляющая граница залегает на глубине 10-13 км и характеризуется граничной скоростью 6.1-6.2 км/с.
Верхний структурный этаж Оротуканского блока магнитный (от 50 до 500 нТл), магнитное поле дифференцированное и состоит из чередования интенсивных линейных локальных преимущественно положительных (до 700 нТл) и отрицательных (до -300 нТл) аномалий. Слой низкоомный (в среднем 50 Ом·м), незначительно дифференцирован по УЭС (от 30 до 150 Ом·м), осложнен высокоомными (200-700 Ом·м) аномалиями (см. рис. 2). Мощность этажа около 15-16 км. Вещество земной коры здесь относительно уплотненное, плот-

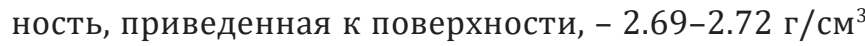
(рис. 3, б). Плотностная граница в среднем на глубине

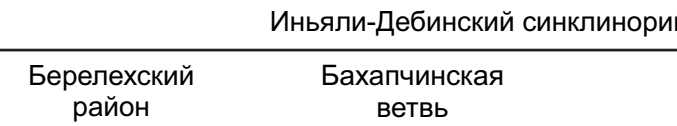

Балыгычанское ветвь

Среднеканская ветвь

Оротуканский блок

(a)
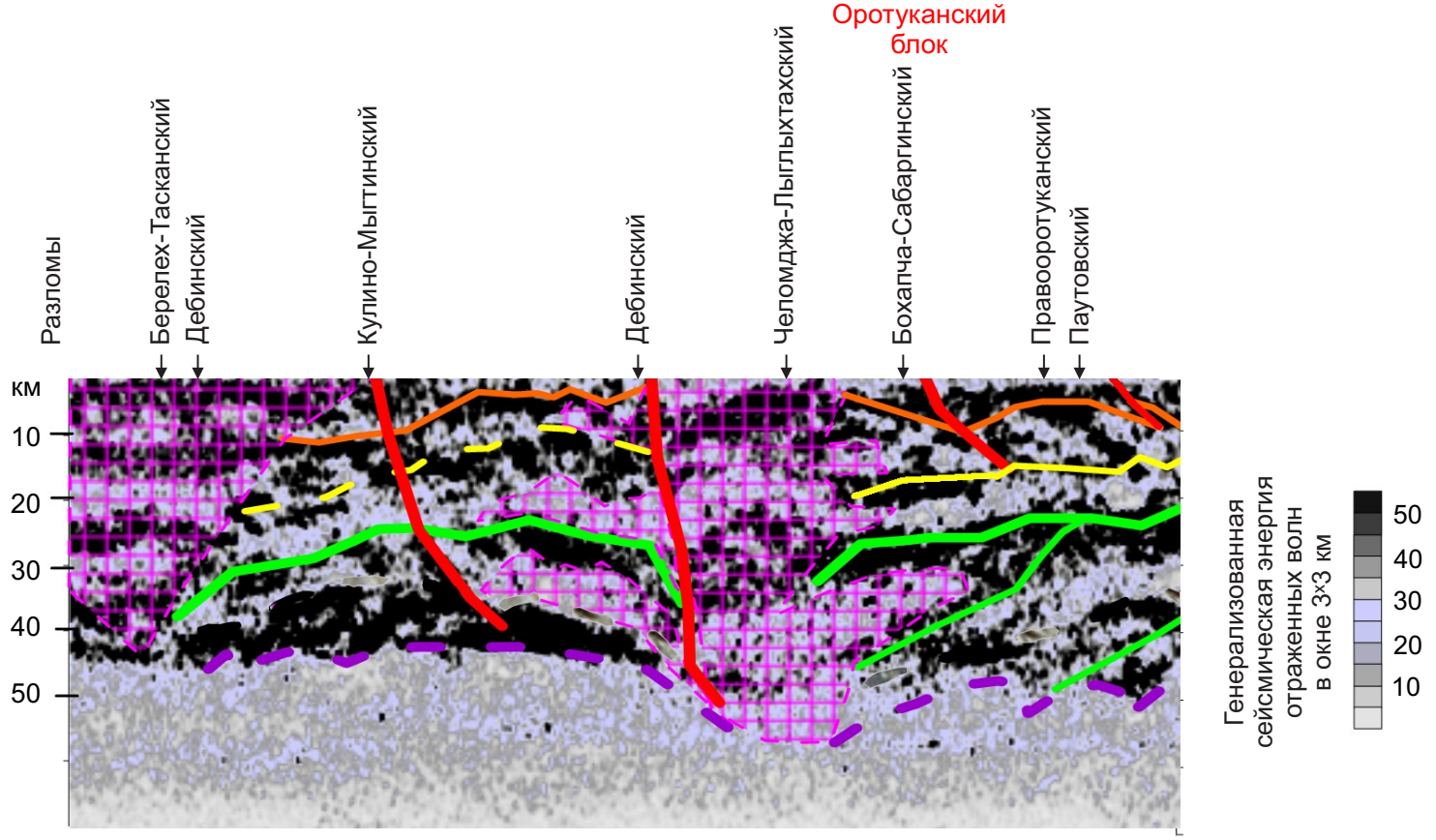

(б)
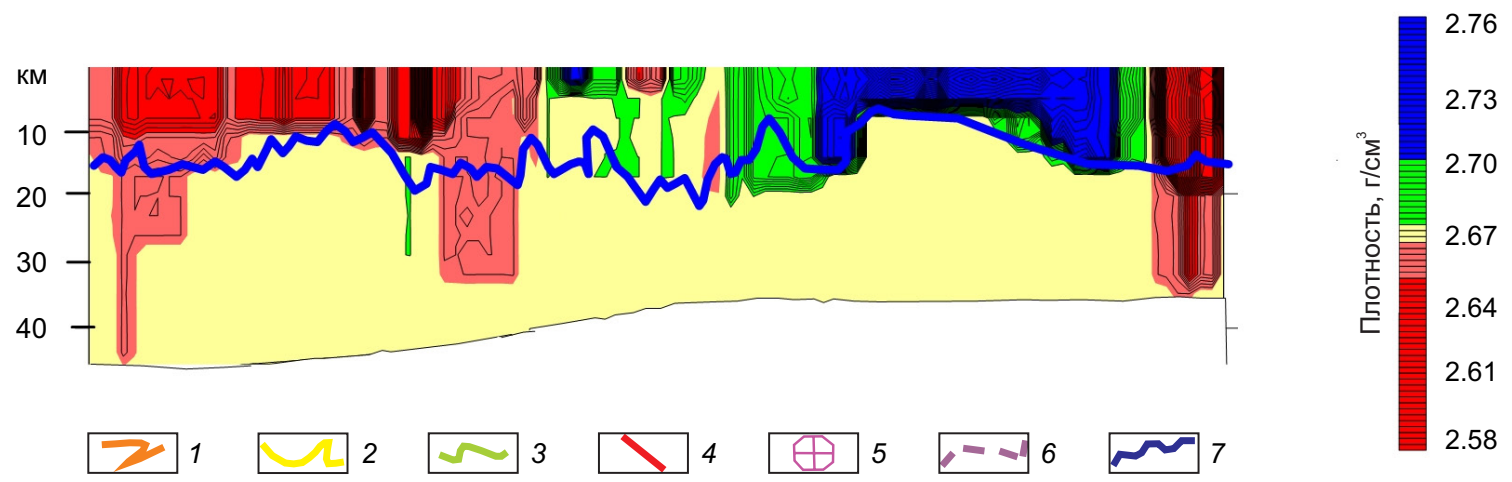

Рис. 3. Интерпретация отражающих уровней энергетического разреза $(a)$ и плотностной разрез (в значениях плотности, приведенных к поверхности) (б) вдоль фрагмента профиля 3-ДВ на участке 2340-2620 км.

1 - подошва покровно-чешуйчатого палеозойского осадочного чехла; 2 - подошва гранитогнейсового слоя земной коры; 3 кровля нижнего слоя коры гранулито-базитового состава; 4 - разрывные нарушения; 5 - мантийное окно; 6 - граница Мохоровичича; 7 - плотностная граница расслоения в земной коре.

Fig. 3. Interpretation of the reflecting levels of the energy (a) and density (reduced to surface) (б) sections along the 2340-2620 km segment of Profile 3-DV.

1 - sole of the Paleozoic sedimentary cover; 2 - sole of the granite-gneiss crustal layer; 3 - roof of the lower granulite-mafic crustal layer; 4 - faults; 5 - mantle window; 6 - Moho boundary; 7 - crustal density boundary. 
4-5 км с погружением до 10-20 км. Слой высокоскоростной. Скорости изменяются в интервале 5.0-5.8 км/с. По данным преломленных волн фиксируются две преломляющие скоростные границы (рис. 3, а). Прежняя граница, являвшаяся первой в структуре Иньяли-Дебинского синклинория, здесь отсутствует (вероятно, она выклинилась). В этом блоке практически к поверхности поднимается граница, прежде названная второй. Она характеризуется граничной скоростью 5.7-5.8 км/с. Следующая преломляющая граница, прежде названная третьей, залегает на глубине 4-5 км и характеризуется граничной скоростью 6.25-6.40 км/с.

Верхний структурный этаж Балыгычанского поднятия слабомагнитный (от -50 до +50 нТл), магнитное поле спокойное, ровное, осложнено редкими единичными линейными и изометричными локальными слабоинтенсивными (до 150 нТл) аномалиями. Слой низкоомный (УЭС до 30 Ом·м) при средней мощности 20 км, осложнен множеством непроводящих (от 1000 до 10000 Ом·м) вертикальных вставок значительных размеров (горизонтальная мощность 10-20 км), уходящих «корнями» в среднюю кору (высокоомное основание) (рис. 2). В плотностном отношении слой разуплотненный. Плотность, приведенная к поверхности,

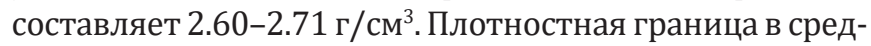
нем на глубине 8-10 км. По скоростным характеристикам является менее высокоскоростным в сравнении с предыдущими блоками. Скорости изменяются в интервале 5.4-6.2 км/с. По данным преломленных волн фиксируются две преломляющих границы (рис. 3, а). Практически у поверхности находится преломляющая граница, характеризующаяся граничной скоростью 5.6-5.8 км/с. На глубине 3-4 км расположена вторая граница с граничной скоростью 6.0-6.2 км/с.

Нижний структурный этаж (средняя, нижняя кора комплексы основания) по блокам имеет следующие характеристики.

Иньяли-Дебинский синклинорий: высокоомный (в среднем более 800 Ом·м) со средней дисперсией параметра УЭС (от 100 до 3000 Ом·м) (см. рис. 2). Местами разуплотненный (в зонах глубинных разломов), в остальных областях средней плотности (плотность, приве-

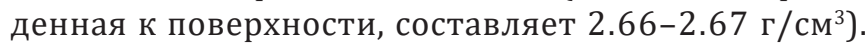
Характеризуется относительно пониженными значениями аномального гравитационного и повышенными значениями аномального магнитного поля (рис. 3,4 ). Низкоскоростной, средняя скорость 6.1-6.3 км/с. Скорость преломленных волн по границе Мохоровичича составляет 8.0-8.3 км/с. Средняя скорость во всей толще коры в этом блоке составляет 6.44-6.46 км/с.

Оротуканский блок: высокоомный (в среднем более 300 Ом·м) с низкой дисперсией параметра УЭС (от 200 до 1000 Ом·м) (см. рис. 2). Уплотненный, плотность 2.672.72 г $/ \mathrm{cm}^{3}$ (см. рис. 3, б). Имеет повышенные значения гравитационного и знакопеременные дифференцированные значения магнитного поля (см. рис. 2; рис. 4). Высокоскоростной, интервальная скорость в средней и нижней коре составляет 6.25-6.50 км/с. Скорость преломленных волн по границе Мохоровичича составляет 8.0-8.1 км/с. Средняя скорость во всей толще коры в этом блоке составляет $\mathrm{V}_{\text {ср }}=6.65$ км $/$ с.

Балыгычанское поднятие: весьма высокоомное (в среднем более 1500 Ом·м) с низкой дисперсией параметра УЭС (от 500 до 3000 Ом·м) (см. рис. 2). Блок средней

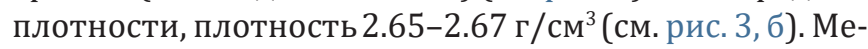
нее высокоскоростной, средняя скорость в средней нижней коре составляет 6.4-6.5 км/с. Скорость преломленных волн по границе Мохоровичича составляет 7.88.3 км/с. Средняя скорость во всей толще коры в этом блоке составляет 6.25-6.4 км/с.

\section{5. ОБСУЖДЕНИЕ РЕЗУЛЬТАТОВ}

Результаты комплексной интерпретации геофизических данных показывают, что территория, по которой проходит северо-восточный участок профиля 3-ДВ, может быть разбита на три принципиально отличающиеся по характеру глубинного строения и поведению отражающих площадок структурные области. Границы выделенных областей выделяются резким изменением пространственного расположения энергетических преград, резким изменением физических свойств вещества - плотности, проводимости, намагниченности. Эти границы пространственно совпадают с положением Умарского и Паутовского разломов соответственно (2460 и 2600 км профиля 3-ДВ) (см. рис. 1).

Первая область расположена преимущественно в западной части листа, представляет Иньяли-Дебинский синклинорий. Вторая - переходная структура между Балыгычанским поднятием и Сугойским синклинорием (относимая в настоящее время к среднеканской ветви Иньяли-Дебинского синклинория). Третья - Балыгычанское поднятие.

В первой области (Иньяли-Дебинский синклинорий) в районе г. Сусуман плотностным моделированием устанавливается глубокая зона разуплотнения в земной коре (средняя плотность 2.58-2.66 г/см³) (см. рис. 3, б). Четко выделяются очертания гранитоидных массивов (Чьорго, Негояхский, Маяк, Трубный, Б. Пороги, Хапчагай, Уаза-Ина, Б. Анначаг). В целом, в данной области земная кора сильно гранитизирована, о чем свидетельствуют гравиметрические и геоэлектрические данные (см. рис. 2). Можно предположить, что уже на глубине 2 км геологическая среда, расположенная в пределах центральной части Иньяли-Дебинского синклинория в диапазоне ПК2380-2440 (и особенно 2420-2440 - район Батолитового пояса), представляет собой область интенсивной гранитизации осадочных пород. Батолитовый пояс по геоэлектрическим данным уверенно выделяется высокоомными локальными аномалиями (ПК2420-2440), сочленяющимися на глубине 17-20 км с породами высокоомного основания (по данным МТЗ), кровля которого совпадает с плотностной границей расслоения в земной коре (гравиметрия) и подошвой гранитогнейсового слоя (сейсмометрия). Возможно, именно здесь происходит изменение 


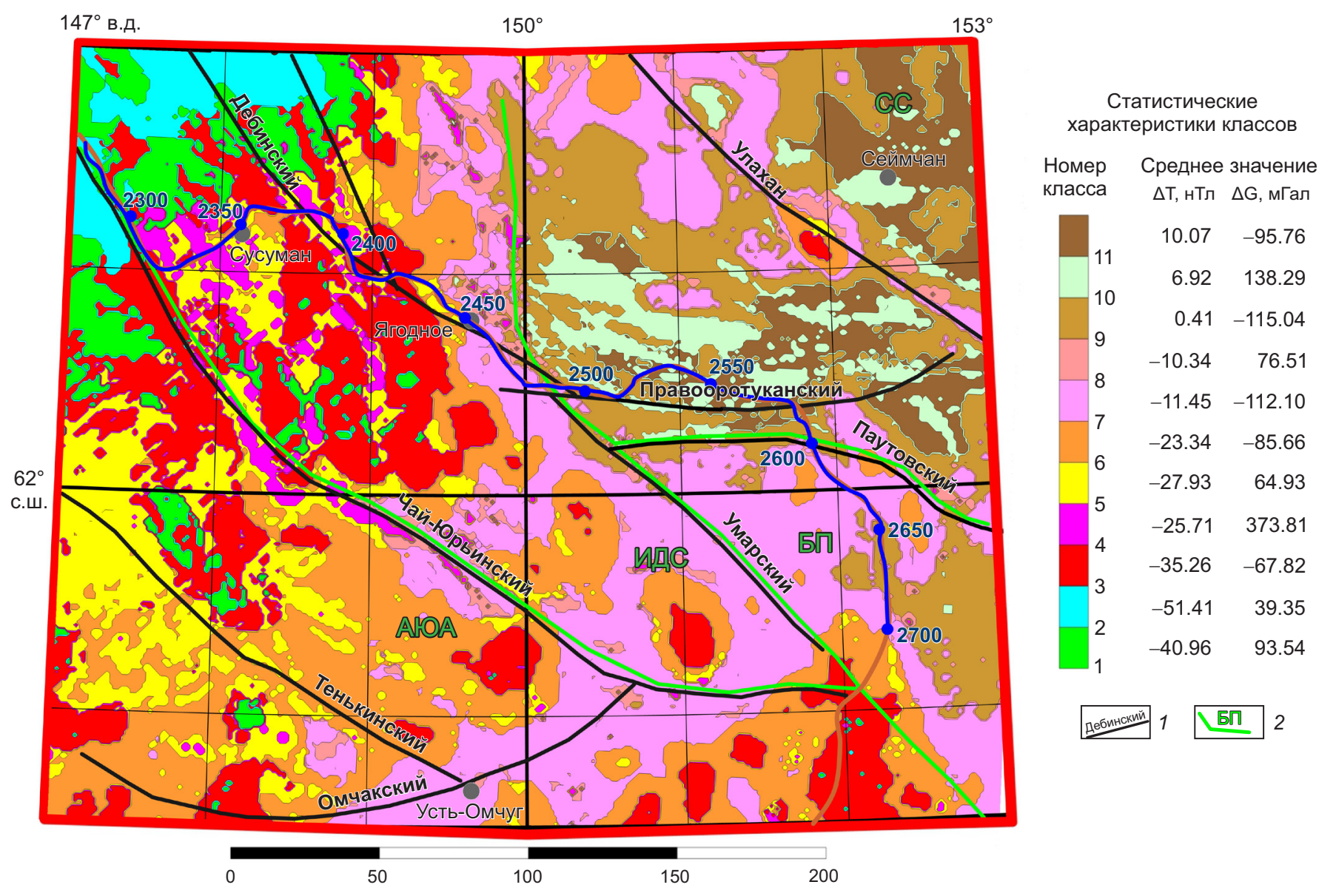

Рис. 4. Карта классов исходных гравитационных и магнитных полей (классификация по А.В. Петрову, разделение многомерных нормальных смесей, КОСКАД 3D).

1 - разрывные нарушения, картируемые на поверхности; 2 - основные тектонические структуры: АЮА - Аян-Юряхский антиклинорий, ИДС - Иньяли-Дебинский синклинорий, БП - Балыгычанское поднятие, СС - Сугойский синклинорий. Геологическая природа выделяемых классов приведена в табл 1.

Fig. 4. Map of the classes of initial gravitational and magnetic fields (classification by A.V. Petrov; division of multivariate normal mixtures; COSCAD 3D).

1 - faults mapped on the surface; 2 - main tectonic structures: АЮА - Ayan-Yuryakh anticlinorium, ИДС - Inyali-Debinsky synclinorium, БП - Balygychan uplift, CС - Sugoi synclinorium. The geological features of the classes are given in Table 1.

Таблица 1. Статистические характеристики классов

Table 1. Statistical characteristics of classes

\begin{tabular}{|c|c|c|c|}
\hline $\begin{array}{l}\text { Номер } \\
\text { класса }\end{array}$ & $\begin{array}{c}\text { Средние значения } \\
\Delta \mathrm{G}, \mathrm{мГал}\end{array}$ & $\begin{array}{c}\text { Средние значения } \\
\Delta \mathrm{T}, \mathrm{H} \text { Л }\end{array}$ & Предполагаемая геологическая природа \\
\hline 1 & -40.96 & 93.54 & $\begin{array}{l}\text { Осадочные породы ИДС при отсутствии гранитоидов, пермские осадки, возможно } \\
\text { близко к поверхности }\end{array}$ \\
\hline 2 & -51.41 & 39.35 & Осадочные породы ИДС, вмещающие маломощные гранитоидные интрузии \\
\hline 3 & -35.26 & -67.82 & $\begin{array}{l}\text { Гранитоидные интрузии, выходящие на поверхность и близко залегающие, обра- } \\
\text { зования ОЧВП (Охотско-Чукотский вулканогенный пояс) }\end{array}$ \\
\hline 4 & -25.71 & 373.81 & $\begin{array}{l}\text { Магнитные образования триаса, сопровождаемые крупными разломами (Чай-Юрь- } \\
\text { инский) }\end{array}$ \\
\hline 5 & -27.93 & 64.63 & Пермские отложения АЮА, магнитные \\
\hline 6 & -23.34 & -85.66 & $\begin{array}{l}\text { Пермские отложения АЮА, немагнитные, и участки насыщения скрытыми грани- } \\
\text { тоидами }\end{array}$ \\
\hline 7 & -11.45 & -112.10 & $\begin{array}{l}\text { Триасовые немагнитные образования, возможно, переход к карбонатному слою, от- } \\
\text { сутствие скрытых гранитоидов }\end{array}$ \\
\hline 8 & -10.34 & 76.51 & Межинтрузивные пространства, возможно, ореолы ороговикованных пород \\
\hline 9 & 0.41 & -115.04 & Влияние мафического основания повышенной плотности, немагнитные породы \\
\hline 10 & 6.92 & -138.29 & Влияние мафического основания повышенной плотности, магнитные породы \\
\hline 11 & 10.07 & -95.76 & Поднятие кровли мафического основания \\
\hline
\end{tabular}


реологических свойств геологической среды и земная кора делится на верхнюю хрупкую зону и подстилающую ее нижнюю, насыщенную флюидами, пластичную зону [Pospeev, 1987, 2004; Shilovsky, 1994; Marquis, Hyndman, 1992; Moroz, Pospeev, 1995]. Выявленные высокоомные аномалии чередуются с зонами электропроводности, содержащими примесные ионные и электронные проводники [Pospeev, 2004], которые отображают ряд разломов верхнекорового и глубинного (сквозькорового) заложения.

Формирование «положительных» форм рельефа высокоомного основания, вероятно, происходило за счет многочисленных разносторонних подвижек вдоль глубинных разрывных нарушений в периоды тектономагматической активизации. В результате этого в верхней (более хрупкой) части земной коры на определенных ослабленных участках создавался избыток свободного пространства, образовывалась трещиноватая среда, которая заполнялась магматическим расплавом, поступавшим из средних и нижних (более пластичных) слоев земной коры. Таким образом, развитие значительных по размерам интрузивных тел батолитового пояса связано с существованием транзита верхнемантийного - нижнекорового субстрата в верхнюю часть земной коры. Вероятнее всего, повышенный тепловой поток (возможно, механической природы) способствовал формированию этой гранитно-метаморфической коллизионной системы. Область отличается повышенным количеством слоев отражающих площадок на скоростных разрезах и практически горизонтальным характером их расположения (см. рис. 3, a).

Вторая область (которую мы предлагаем назвать Оротуканский блок) выделяется севернее Паутовского разлома и устанавливается как блок более плотной (в сравнении с предыдущей областью) земной коры (средняя модельная плотность пород 2.72-2.74 г/ $\mathrm{cm}^{3}$ ) с точечным внедрением небольших по площади и мощности интрузивов (см. рис. 3 , б). На южном контакте гранитоидного интрузива Маяк устанавливается аномальная зона уплотнения 2.72-2.80 г/ $\mathrm{cm}^{3}$, которая может быть объяснена присутствием здесь тел коллизионных габброидов [Zagruzina, 1973; Lychagin, 1993; Izokh et al., 2012].

Третья область представляет собой Паутовский горст Балыгычанского поднятия. Плотность блоков земной коры здесь выше, чем в первой области, но ниже, чем во второй (см. рис. 3, б). Четко выделяются границы не вскрытых на поверхности Приискательского и Паутовского гранитоидных массивов (средняя модельная плотность (2.61-2.67 г/см ${ }^{3}$ ), разделенных областью триасово-юрских отложений сравнительно небольшой мощности (7-8 км) со средней модельной плотностью

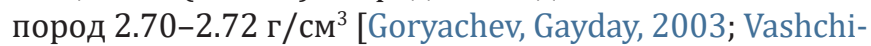
lov et al., 2008]. С запада область ограничена Умарским разломом, на севере - Паутовским разломом. В третьей области наблюдается увеличение хаотичности в расположении отражающих площадок на скоростном разрезе, что не было характерно для первой области, где также отмечались вскрытые и не вскрытые на поверхности интрузивы (см. рис. 3, а).

Результаты комплексной интерпретации показывают, что Умарский разлом представляет собой зону разрывных нарушений шириной порядка 7-16 км.

Представленные магнитотеллурические данные (см. рис. 2) в совокупности с иными геолого-геофизическими данными показывают, что в пределах Иньяли-Дебинского синклинория и особенно в районе его бохапчинской ветви (области развития гранитоидного магматизма) высокоомное основание, очевидно, насыщено преимущественно гранитизированным веществом.

Высокоомное основание среднеканской ветви Иньяли-Дебинского синклинория (названная авторами Оротуканский блок) имеет преимущественно мафический состав [Mikhailov, Goryachev, 2000] в совокупности с магматическими очагами среднего - основного состава (см. рис. 2, 4).

Сравнение данных геоэлектрических наблюдений (см. рис. 2) с результатами сейсморазведки и интерпретации гравиметрических данных (см. рис. 3) позволяет отметить, что глубины границ комплексов основания, распространение областей гранитизации верхней части земной коры, совокупная мощность средней и нижней коры (граница Мохо), а также положение разрывных нарушений глубинного заложения согласуются между собой.

Некоторые расхождения границ разных методов намечаются в пределах зон разрыва сплошности границы Мохо и наличия элементов литосферного (электро) проводящего слоя (ЛПС). Это может быть связано с длительным и интенсивным тепломассопереносом вещества из верхней мантии в пространство нижней и средней коры. Транзит магматического расплава осуществлялся по каналам глубинных разломов, фиксирующихся вертикальными зонами высокой электропроводимости и сейсмической прозрачности, пересекающих всю кору и уходящих в верхнюю мантию.

Полученные нами данные говорят о том, что среднеканская ветвь Иньяли-Дебинского синклинория (Оротуканский блок) по своему строению гораздо ближе к структурам Сугойского синклинория, а не к структурам основной ветви Иньяли-Дебинского синклинория. Зона имеет «тяжелый» (положительные региональные аномалии поля силы тяжести) нижний структурный этаж (фундамент?) и является «дифференцированно» магнитным (полосовое чередование интенсивных линейных положительных и отрицательных локальных аномалий магнитного поля).

По данным магнитометрических наблюдений (интервал ПК 2580-2620) с учетом плотностных и магнитных характеристик уверенно устанавливается, что сочленение выделяемого Оротуканского блока, относимого сейчас к среднеканской ветви Иньяли-Дебинского синклинория, с Балыгычанским поднятием проходит по плоскости Паутовского (ПК 2600), а не Правооротуканского разлома, как предполагали предыдущие 
исследователи [Geological Map..., 1998; State Geological Мap, 2008].

На это же указывает и различие в гравимагнитных характеристиках трех указанных выше областей, которые можно наблюдать при сравнении классов геофизических параметров с геологической картой (см. рис. 4). Проведенный анализ магнитотеллурических, гравимагнитных и сейсмических данных, различие в классах геофизических параметров вновь выступают в пользу отнесения современной среднеканской ветви ИньялиДебинского синклинория к отдельному блоку.

Аналогичная точка зрения высказана ранее [Egorov, Ganov, 2003; Biakov, 2004]. Этими исследователями отмечалось, что среднеканская ветвь, как троговый прогиб, по-видимому, развивалась в значительной степени автономно от структур Иньяли-Дебинского синклинория и отличается от последнего более дифференцированными мощностями отложений верхоянского комплекса, морфологией поверхности и составом комплексов основания. Здесь наблюдается слабое проявление процессов гранитизации коры [Khasanov, Sharafutdinov, 2011; Khasanov, 2013], что и обусловливает повышенную плотность пород этого блока в сравнении с блоками Иньяли-Дебинского синклинория.

Таким образом, указанные факты позволяют предполагать, что так называемая среднеканская ветвь, скорее всего, является отдельной структурой Сугойского синклинория.

\section{6. ЗАКЛЮЧЕНИЕ}

Сравнительный анализ характеристик элементов глубинного строения территории (мощность складчато-метаморфического комплекса, границы комплексов основания, положения в разрезе разрывных нарушений глубинного заложения), выявленных различными геофизическими методами (геоэлектрика, грави- и магнитометрия, сейсмика), показывает, что они согласуются между собой. Исключение составляют зоны разрыва сплошности границы Мохо и наличия ЛПС, что может быть связано с транзитом магматического расплава в верхние горизонты земной коры.

Геофизические данные, лежащие в основе комплексного анализа, выполненного в работе (магнитные, электрические, плотностные и скоростные), позволяют выделить три геофизически различных блока земной коры, которые в первом приближении соответствуют поверхностным тектоническим структурам.

Блок, относимый к Иньяли-Дебинскому синклинорию, в верхней части земной коры малоплотный, магнитный, низкоомный (с наличием как мелких, так и крупных высокоомных аномалий), низкоскоростной. В нижней коре со средними плотностными характеристиками (с единичными отрицательными аномалиями, уходящими на всю мощность коры в зонах глубинных разломов), высокоомный, высокоскоростной.

Блок, относимый в настоящее время к среднеканской ветви Иньяли-Дебинского синклинория, является в верхних горизонтах плотным, магнитным, низкоомным (с наличием высокоомных аномалий), высокоскоростным. В нижней коре уплотненный, высокоомный (практически не осложненный аномалиями), высокоскоростной.

Блок, относимый к Балыгычанскому поднятию, в верхней части коры менее плотный, слабомагнитный, низкоомный (с множеством вертикальных непроводящих аномалий, уходящих «корнями» в среднюю кору), менее высокоскоростной. В нижней части коры менее плотный, высокоомный (практически не осложненный аномалиями), менее высокоскоростной.

Указанные особенности дают основание для выдвижения предложения об отнесении существующей сегодня среднеканской ветви Иньяли-Дебинского синклинория к отдельной структуре Сугойского синклинория, представляющей его юго-западный фланг (краевую составляющую) - Оротуканский блок с границей, проходящей по плоскости Паутовского разлома.

Проведенный комплексный анализ геофизических данных показал необходимость дальнейшей работы с полученной информацией. Как известно, на северовосточном участке около 50 \% профиля расположено вдоль разрывных нарушений. В этом случае встает вопрос о том, какую часть земной коры относительно разлома отражают результаты интерпретации первичных данных (сейсмических, магнитных, электрических и гравитационных). Целесообразно рассмотреть только отдельные участки профиля, секущие направление размещения основных структур (2100-2260 км, 23402370 км, 2600-2700 км). Вероятно, это приведет к получению новых данных о различии в строении отдельных структур изучаемой площади.

\section{7. ЛИТЕРАТУРА / REFERENCES}

Biakov A.S., 2004. Permian Deposits of the Balygychan Uplift (Northeast Asia). North-East Interdisciplinary Scientific Research Institute FEB RAS, Magadan, 89 p. (in Russian) [Бяков А.С. Пермские отложения Балыгычанского поднятия (северо-восток Азии). Магадан: СВКНИИ ДВО РАН, 2004. 89 c.].

Bol'shakov V.N., 1988. Report on the Results of Seismic Surveys to Study the Deep Geological Structure of the InyaliDebinsky Synclinorium and Adjacent Structures in 19851988. CGE, Khasyn, 187 p. (in Russian) [Большаков В.Н. Отчет о результатах проведения сейсморазведочных работ по изучению глубинного геологического строения Иньяли-Дебинского синклинория и сопредельных структур в 1985-1988 гг. Хасын: ЦГЭ, 1988. 187 с.].

Chanyshev I.S. etal., 1984. Research Report - Assessment of the Prospects for Gold-Ore Regions of Central Kolyma Based on a Complex of Geological, Geochemical and Geophysical Criteria. Scientific Report. Territorial Geological Fund, Magadan, 265 р. (in Russian) [Чанышев И.С. и др. Отчет о научно-исследовательской работе «Оценка перспектив золоторудных районов Центральной Колымы на основе комплекса геологических, геохимических и геофизических критериев». Магадан: ТГФ, 1984. 265 c.]. 
Chekhov A.D., 2000. Tectonic Evolution of Northeast Asia. Nauchny Mir, Moscow, 198 p. (in Russian) [Чехов А.Д. Тектоническая эволюция северо-востока Азии. М.: Научный мир, 2000. 198 с.].

Egorov V.N., Ganov A.P., 2003. On the Origin of the Srednekansky Branch of the Inyali-Debinsky Synclinorium. In: Geodynamics, Magmatism and Minerageny of the Continental Margins of the North Pacific. Proceedings of the All-Russia Meeting (June 03-06, 2003). Vol. 1. Magadan, p. 87-89 (in Russian) [Егоров В.Н., Ганов А.П. К вопросу о природе среднеканской ветви Иньяли-Дебинского синклинория // Геодинамика, магматизм и минерагения континентальных окраин севера Пацифики: Материалы Всероссийского совещания (03-06 июня 2003 г.). Магадан, 2003. T. 1. C. 87-89].

Ganov A.P., 2001. Information Report on the Results of Seismic Surveys to Study the Deep Structure of the AyanYuryakh Anticlinorium, Adjacent Parts of the Taryn-Detrinsky Synclinorium, and the Omulev Uplift in 1988-1993. Magadan, 108 p. (in Russian) [Ганов А.П. Информационный отчет о результатах сейсморазведочных работ по изучению глубинного строения Аян-Юряхского антиклинория, сопредельных частей Тарыно-Детринского синклинория и Омулевского поднятия в 1988-1993 гг. Магадан, 2001. 108 с.].

Gayday N.K., 2010. New Interpretive Gravimetry. Concepts. Capabilities. Prospects for Use. Bulletin of the NorthEastern State University 13 (Spec. Iss.), 10-14 (in Russian) [Гайдай Н.К. Новая интерпретационная гравиметрия. Понятия. Возможности. Перспективы использования // Вестник Северо-Восточного государственного университета. 2010. № 13 (спецвыпуск). С. 10-14].

Gayday N.K., 2017. Assessment of the Localization of Hypocenters of Crustal Earthquakes Relative to the Depth and Relief of the Border Density Stratification in the Crust of the Northeastern Section of the Reference Geological-Geophysical Profile 3-DV. Geodynamics \& Tectonophysics 8 (4), 849-861 (in Russian) [Гайдай Н.К. Оценка локализации гипоцентров коровых землетрясений относительно глубины и рельефа плотностной границы расслоения в земной коре северо-восточного участка опорного геолого-геофизического профиля 3-ДВ // Геодинамика и тектонофизика. 2017. Т. 8. № 4. С. 849-861]. https://doi. org/10.5800/GT-2017-8-4-0320.

Geological Map of the Northeastern Regions of the USSR, 1980. Scale 1:1500000. VSEGEI Publishing House, Leningrad (in Russian) [Геологическая карта северо-востока СССР. Масштаб 1:1500000. Л.: Изд-во ВСЕГЕИ, 1980].

Geological Map, and Map of Mineral Resources of the Kolyma-Omolon Region, 1998. Scale 1:500000. Explanatory Note. North-Eastern Research Center of Mineral Resources, Magadan, 270 p. (in Russian) [Геологическая карта и карта полезных ископаемых Колымо-Омолонского региона масштаба 1:500 000: Объяснительная записка. Магадан: Северо-Восточный научно-исследовательский центр минерального сырья, 1998. 270 с.].

Goryachev N.A., 2003. Origin of Gold-Quartz Vein Belts of the North Pacific. North-East Interdisciplinary Scientific
Research Institute FEB RAS, Magadan, 143 p. (in Russian) [Горячев Н.А. Происхождение золото-кварцевых жильных поясов Северной Пацифики. Магадан: СВКНИИ ДВО PAH, 2003. 143 c.].

Goryachev N.A., Byalobzhesky S.G., Kuznetsov V.M., Palymsky B.F., Feldman L.L., 2007. Features of the Deep Structure of Continental-Margin Magmatic Arcs - Case of the Northern Okhotsk Region. In: A.S. Sal'nikov (Ed.), Structure of the Earth's Crust in the Magadan Sector of Russia from Geological and Geophysical Data. Nauka, Novosibirsk, p. 118-133 (in Russian) [Горячев Н.А., Бялобжеский С.Г., Кузнецов В.М., Палымский Б.Ф., Фельдман Л.Л. Особенности глубинного строения окраинно-континентальных магматических дуг на примере Северного Приохотья // Структура и строение земной коры Магаданского сектора России по геолого-геофизическим данным / Ред. А.С. Сальников. Новосибирск: Наука, 2007. С. 118-133].

Goryachev N.A., Gayday N.K., 2003. Relief of the Tops of Closed Plutons in the Core of the Orotukan Uplift and Locations of Tin-Rare-Metal Mineralization. Kolyma VESTI, Magadan 24, 2-4 (in Russian) [Горячев Н.А., Гайдай Н.К. Рельеф кровли невскрытых плутонов ядра Оротуканского поднятия и локализация проявлений олово-редкометалльной минерализации // Колымские ВЕСТИ. Магадан, 2003. № 24. C. 2-4].

Goryachev N.A., Palymsky B.F., Petrov A.N., Khasanov I.M., 2016. Fault Ensembles of the Okhotsk-Kolyma Region. Bulletin of the North-Eastern Scientific Center of FEB RAS 1, 3-15 (in Russian) [Горячев Н.А., Палымский Б.Ф., Петров А.Н., Хасанов И.М. Ансамбли разломов Охотско-Колымского региона // Вестник Северо-Восточного научного центра ДВО РАН. 2016. № 1. С. 3-15].

Goshko E.Yu., Efimov A.S., Sal'nikov A.S., 2014. The Recent Structure and the Assumed History of Formation of the Crust in the South-Eastern Segment of the North Asian Craton along Reference Profile 3-DV. Geodynamics \& Tectonophysics 5 (3), 785-798 (in Russian) [Гошко Е.Ю., Ефимов А.С., Сальников А.С. Современная структура и предполагаемая история формирования земной коры юговостока Северо-Азиатского кратона вдоль опорного профиля 3-ДВ // Геодинамика и тектонофизика. 2014. T. 5. № 3. C. 785-798]. https://doi.org/10.5800/GT-20145-3-0155.

Goshko E.Yu., Markov V.M., Strazhnikova I.N., Sagaidachnaya O.M., Salnikov A.S., 2008. Method for Seismic Data Processing. Patent for Invention No. 2324205 (RU). Discovery and Inventions Bulletin 13 (in Russian) [Гошко E.Ю., Mарков В.М., Стражникова И.Н., Сагайдачная О.М., Сальников А.С. Способ обработки сейсмических данных: Патент на изобретение № 2324205 (RU) // Бюллетень «Открытия и изобретения». 2008. № 13].

Izokh A.E., Goryachev N.A., Al'shevskii A.V., Akinin V.V., 2012. Sokhatiny Differentiated Gabbro-Monzodiorite Intrusion from the Example of Sin-Batholitic Gabbroids of Yano-Kolymskaya System. Doklady Earth Sciences 444, 549552. https://doi.org/10.1134/S1028334X1205011X.

Khanchuk A.I. (Ed.), 2006. Geodynamics, Magmatism and Metallogeny of the Eastern Regions of Russia. Dal'nauka, 
Vladivostok, 981 p. (in Russian) [Геодинамика, магматизм и металлогения востока России / Ред. А.И. Ханчук. Владивосток: Дальнаука, 2006. 981 с.].

Khasanov I.M., 2013. Geoelectric Features of Deep Structures in the Southern Part of the Yana-Kolyma Fold Structure. In: Readings in Memory of Academician K.V. Simakov. Proceedings of the All-Russia Scientific Conference (November 26-28, 2013). North-Eastern Scientific Center FEB RAS, Magadan, p. 72-73 (in Russian) [Хасанов И.М. Геоэлектрические особенности глубинного строения структур юга Яно-Колымской складчатой структуры // Чтения памяти академика К.В. Симакова: Материалы докладов Всероссийской научной конференции (26-28 ноября 2013 г.). Магадан: СВНЦ ДВО РАН, 2013. C. 72-73].

Khasanov I.M., Sharafutdinov V.M., 2011. The Deep Structure of the Southeastern Part of the Yana-Kolyma Fold System from Geophysical Data and the Characteristic Features of the Structure of Gold-Ore Nodes. Proceedings of the Kazan University. Natural Sciences Series 153 (3), 230-246 (in Russian) [Хасанов И.М., Шарафутдинов В.М. Глубинное строение юго-востока Яно-Колымской складчатой системы по геофизическим данным и характерные особенности строения золоторудных узлов // Ученые записки Казанского университета. Серия Естественные науки. 2011. Т. 153. Кн. 3. С. 230-246].

Kuznetsov V.L., Sal'nikov A.S., Staroseltsev V.S., Surkov V.S., Lipilin A.V., Emanov A.F., Soloviev V.M., 2010. The Crustal Structure at the Cross-Section of the Reference Profile 2-DV from DSS Data. Geology and Mineral Resources of Siberia 2, 21-30 (in Russian) [Кузнецов В.Л., Сальников А.С., Старосельцев B.С., Сурков В.С., Липилин А.В., Еманов А.Ф., Соловьев В.М. Строение земной коры в сечении опорного профиля 2-ДВ по данным ГСЗ // Геология и минерально-сырьевые ресурсы Сибири. 2010. № 2. С. 21-30].

Lychagin P.P., 1993. Layered Ultramafic-Mafic Bodies in the Mesozoids of the Northeastern Regions of Russia. NorthEast Interdisciplinary Scientific Research Institute FEB RAS, Magadan, p. 140-157 (in Russian) [Лычагин П.П. Расслоенные ультрамафит-мафитовые тела в мезозоидах северо-востока России. Магадан: СВКНИИ ДВО РАН, 1993. C. 140-157].

Marquis G., Hyndman R.D., 1992. Geophysical Support for Aqueous Fluids in the Deep Crust: Seismic and Electrical Relationships. Geophysical Journal International 111 (1), 91-105. https://doi.org/10.1111/j.1365-246X.1992. tb00716.x.

Mikhailov B.K., Goryachev N.A., 2000. Interpretation of the Geophysical Fields of the Mesozoids of Northeast Asia and the Position of Gold-Quartz Mineralization. In: Gold Mineralization and Granitoid Magmatism of the North Pacific. Geology, Geochronology, and Geochemistry. Proceedings of the All-Russia Meeting. Vol. 1. North-East Interdisciplinary Scientific Research Institute FEB RAS, Magadan, p. 83-86 (in Russian) [Михайлов Б.К., Горячев Н.А. Интерпретация геофизических полей мезозоид северовостока Азии и позиция золото-кварцевого оруденения // Золотое оруденение и гранитоидный магматизм
Северной Пацифики. Геология, геохронология, геохимия: Труды Всероссийского совещания. Магадан: СВКНИИ ДВО РАН, 2000. Т. 1. С. 83-86].

Moroz Yu.F., Pospeev A.V., 1995. Deep Electrical Conductivity of East Siberia and the Far East of Russia. Tectonophysics 245 (1-2), 85-92. https://doi.org/10.1016/00401951(94)00143-W.

Nokleberg W.J., Parfenov L.M., Monger J.W., Norton I.O., Khanchuk A.I., Stone D.B., Scotese C.R., Scholl D.W., Fujita K., 2000. Phanerozoic Tectonic Evolution of the Circum-North Pacific. United States Geological Survey 1626, 122 p.

Parfenov L.M., Berzin N.A., Khanchuk A.I., Badarch G., Belichenko V.G., Bulgatov A.N., Dril' S.I., Kirillova G.L., Kuzmin M.I., Nokleberg U., Prokopiev A.V., Timofeev V.F., Tomurtogoo O., Yan H., 2003. Model of Formation of Orogenic Belts of Central and Northeast Asia. Russian Journal of Pacific Geology 22 (6), 7-41 (in Russian) [Парфенов Л.М., Берзин Н.А., Ханчук А.И., Бадарч Г., Беличенко В.Г., Булгатов А.Н., Дриль С.И., Кириллова Г.Л., Кузьмин М.И., Ноклеберг У., Прокопьев А.В., Тимофеев В.Ф., Томуртогоо О., Янь Х. Модель формирования орогенных поясов Центральной и Северо-Восточной Азии // Тихоокеанская геология. 2003. Т. 22. № 6. С. 7-41].

Petrov A.V., 1996. Methods of Multivariate Dispersion Analysis in Algorithms for Complex Interpretation of Geophysical Observations. Russian Geophysics 1, 19-22 (in Russian) [Петров А.В. Методы многомерного дисперсионного анализа в алгоритмах комплексной интерпретации геофизических наблюдений // Геофизика. 1996. № 1. C. 19-22].

Pospeev A.V., 1987. Electrical Conductivity of the Crust and Mantle along the Chara-Vanino Profile. Russian Journal of Pacific Geology 6, 109-112 (in Russian) [Поспеев А.В. Электропроводность земной коры и мантии по профилю Чара - Ванино // Тихоокеанская геология. 1987. № 6. C. 109-112].

Pospeev A.V., 2004. Geological Aspects of the Geoelectrics of the Earth's Upper Lithosphere. Russian Geophysics 4, 3538 (in Russian) [Поспеев А.В. Геологические аспекты геоэлектрики верхней литосферы Земли // Геофизика. 2004. № 4. C. 35-38].

Sakhno O.V., 1983. Calculation of Gravitational Effect $\Delta \mathrm{g}$ from a Finite Number of Triangular Prisms. In: Geophysical Studies of the Block-Layered Structure of the Lithosphere. Magadan, p. 110-117 (in Russian) [Сахно О.В. Вычисление гравитационного эффекта $\Delta \mathrm{g}$ от конечного числа треугольных призм // Геофизические исследования блоково-слоистой структуры литосферы. Магадан, 1983. C. 110-117].

Sal'nikov A.S., Starosel'tsev V.S., Sobolev P.N. et al., 2014. Report on the Results of Work to Establish the Geological and Geophysical Reference Profile 3 DV (Northeastern Segment). Siberian Research Institute of Geology, Geophysics and Mineral Resources, Novosibirsk (in Russian) [Сальников А.С., Старосельцев В.С., Соболев П.Н. и др. Отчет о результатах работ по объекту «Создание опорного геолого-геофизического профиля 3 ДВ (северо-восточный участок)». Новосибирск: СНИИГГиМС, 2014]. 
Shilovsky A.P., 1994. Deep Electrical Conductivity of the Siberian Platform. Izvestiya, Physics of the Solid Earth 6, 102-109 (in Russian) [Шиловский А.П. Глубинная электропроводность Сибирской платформы // Физика Земли. 1994. № 6. С. 102-109].

Shpilko L.G., 1991. Elements of the Tectonic Structure of the Ayan-Yuryakh Anticlinorium (from Geophysical Data). In: Materials on Geology and Mineral Resources of the Northeastern Regions of the USSR. Vol. 27. North-East Interdisciplinary Scientific Research Institute of the Far East Scientific Center of the USSR Academy of Sciences, Magadan, 56-63 (in Russian) [Шпилько Л.Г. Элементы структурно-тектонического строения Аян-Юряхского антиклинория (по геофизическим данным) // Материалы по геологии и полезным ископаемым северо-востока СССР. Магадан: СВКНИИ ДВНЦ АН СССР, 1991. Вып. 27. С. 56-63].

Staroseltsev V.S., Dolgushin S.S., Sadur O.G., 2007. Deep Structure of the Crust at the 810-1100 km Segment of the 2-DV Profile According to Mathematical Modeling Based on Seismic and Gravimagnetic Data. In: A.S. Sal'nikov (Ed.), Structure of the Earth's Crust of the Magadan Sector of Russia from Geological and Geophysical Data. Nauka, Novosibirsk, 110-117 (in Russian) [Старосельцев B.С., Долгушин C.C., Садур О.Г. Глубинное строение земной коры фрагмента профиля 2-ДВ (810-1100 км) на основе математического моделирования по сейсмическим и гравимагнитным данным // Структура и строение земной коры Магаданского сектора России по геолого-геофизическим данным / Ред. А.С. Сальников. Новосибирск: Наука, 2007. C. 110-117].

State Geological Map of the Russian Federation, 2008. Verkhoyansk-Kolyma Series. Scale 1:1000000. Sheet P-56 (Seimchan). VSEGEI Publishing House, Saint Petersburg (in Russian) [Государственная геологическая карта Российской Федерации. Масштаб 1:1000000. Серия ВерхояноКолымская. Лист Р-56 (Сеймчан). СПб.: Изд-во ВСЕГЕИ, 2008].

Surkov V.S., Sal'nikov A.S., Kuznetsov V.L., Lipilin A.V., Seleznev V.S., Emanov A.F., Soloviev V.M., 2007. The Crustal Structure of the Magadan Sector of the Northeastern Regions of Russia from DSS Data. In: A.S. Sal'nikov (Ed.), Structure of the Earth's Crust of the Magadan Sector of Russia from Geological and Geophysical Data. Nauka, Novosibirsk, 13-21 (in Russian) [Сурков B.С., Сальников А.С., Кузнецов В.Л., Липилин А.В., Селезнев В.С., Еманов А.Ф.,
Соловьев В.М. Строение земной коры Магаданского сектора северо-востока России по данным ГСЗ // Структура и строение земной коры Магаданского сектора России по геолого-геофизическим данным / Ред. А.С. Сальников. Новосибирск: Наука, 2007. С. 13-21].

Suvorov V.D., Mel'nik E.A., Sal'nikov A.S., 2014. The Structure of the Upper Crust According to the KMPV Data along the 3-DV Profile (Skovorodino - Tommot - Yakutsk - Susuman Myakit). In: Geophysical Methods for Studying the Earth's Crust. Proceedings of the All-Russian Conference Dedicated to the 100th Anniversary of the Birth of Academician N.N. Puzyrev (December 8-13, 2014). IPGG SB RAS, Novosibirsk, 264-268 (in Russian) [Суворов В.Д., Мельник Е.А., Сальников А.С. Строение верхней части земной коры по данным КМПВ вдоль профиля 3-ДВ (Сковородино - Томмот Якутск - Сусуман - Мякит) // Геофизические методы исследования земной коры: Материалы Всероссийской конференции, посвященной 100-летию со дня рождения академика Н.Н. Пузырева (8-13 декабря 2014 г.). Новосибирск: ИНГГ СО РАН, 2014. С. 264-268].

Vaschilov Yu.Ya., 1984. Block-Layered Model of the Earth's Crust and Upper Mantle. Nauka, Moscow, 238 p. (in Russian) [Ващилов Ю.Я. Блоково-слоистая модель земной коры и верхней мантии. М.: Наука, 1984. 238 с.].

Vaschilov Yu.Ya., 2005. The New Interpretive Gravimetry - Instead of and Side-by-Side with the Deep Seismic Research. Paper 1. The New Interpretive Gravimetry Methods. Bulletin of the North-Eastern Scientific Center FEB RAS 3, 2-16 (in Russian) [Ващилов Ю.Я. Новая интерпретационная гравиметрия - вместо и вместе с глубинными сейсмическими исследованиями. Статья 1. Методические основы новой интерпретационной гравиметрии //Вестник Северо-Восточного научного центра ДВО РАН. 2005. № 3. C. 2-16].

Vashchilov Yu.Ya., Gaidai N.K., Sakhno O.V., 2008. ThreeDimensional Deep Density Model of the Pautovaya Horst and Its Geological Interpretation (Northeast Russia). Russian Journal of Pacific Geology 2 (4), 299-313. https://doi. org/10.1134/S1819714008040039.

Zagruzina I.A., 1973. Magmatic Formations of the Shturmovsky Region. In: Magmatism of the Northeastern Regions of the USSR. Nauka, Moscow, 133-147 (in Russian) [Загрузина И.А. Магматические образования Штурмовского района // Магматизм северо-востока СССР. М.: Наука, 1973. C. 133-147]. 